\title{
IDENTIFIKASI BUDAYA ORGANISASI PADA BADAN KEPEGAWAIAN PENDIDIKAN DAN PELATIHAN (BKPP) KABUPATEN SRAGEN DENGAN MENGGUNAKAN ORGANIZATIONAL CULTURAL ASSESSMENT INSTRUMENT (OCAI)
}

\author{
Nur Endah Widyastuti \\ Widyaiswara BKPP Kabupaten Sragen \\ nurendahw@gmail.com
}

\begin{abstract}
Abstrak. Pencapaian tujuan atau kinerja organisasi dipandang tidak lagi hanya tergantung pada system pembagian kerja saja namun juga pada aspek manusia, selaku penggerak organisasi. Sebagai organisasi perangkat daerah yang mengalami perubahan struktur beserta tugas pokok dan fungsi, BKPP Kabupaten Sragen menghadapi perubahan dalam perumusan rencana strategisnya sehingga hal ini menjadi momentum pengenalan budaya organisasi dan pengintegrasiannya dalam strategi pencapaian target kinerja yang ditetapkan dalam perencanaan. Kajian ini bertujuan untuk mengenali budaya organisasi yang saat ini berlaku di BKPP Kabupaten Sragen dan tipe budaya organisasi yang menjadi harapan di masa mendatang. Dengan responden seluruh pegawai pada BKPP Kabupaten Sragen, pengidentifikasian tipe budaya organisasi dilakukan dengan menggunakan instrument Organizational Cultural Assessment Instrument (OCAI) yang dikembangkan oleh Kim Cameron dan Robert Quinn. Dari hasil penelitian diperoleh hasil budaya organisasi yang dominan di BKPP Kabupaten Sragen saat ini adalah tipe Clan yang mengutamakan suasana kekeluargaan, komitmen bersama, partisipasi dan pengembangan sumber daya manusia. Harapan para pegawai di masa mendatang juga tidak berubah, namun budaya hierarchy saat ini berkurang perannya sementara tipe budaya adhocracy semakin meningkat. Identifikasi ini diharapkan dapat menjadi masukan bagi pimpinan dan manajemen dalam merumuskan strategi pencapaian kinerja organisasi.
\end{abstract}

\section{Kata kunci : budaya organisasi, strategi pencapaian kinerja, OCAI.}

Abstract. Achievement of organizational goals or performance is seen no longer only depends on the system of division of labor alone but also on the human aspect, as the organizer of the organization. As a regional apparatus organization undergoing structural changes along with its main duties and functions, BKPP of Sragen regency faces changes in the formulation of its strategic plan so that it becomes the momentum of the introduction of organizational culture and its integration in the strategy of achieving the performance targets set out in the planning. This study aims to identify the current organizational culture in BKPP of Sragen regency and the type of organizational culture that is expected in the future. With respondents of all employees at BKPP of Sragen regency, the identification of organizational culture type was done by using Organizational Cultural Assessment Instrument (OCAI) instrument developed by Kim Cameron and Robert Quinn. From the research result, the result of dominant organizational culture in BKPP of Sragen Regency is Clan type which prioritizes family atmosphere, mutual commitment, participation and human resource development. The expectations of future employees are also unchanged, but the current hierarchy culture diminishes its role as the type of ad hoc culture increases. This identification is expected to be an input for leadership and management in formulating strategies for achieving organizational performance.

Keywords : Organizational culture, performance achievement strategy, OCAI 


\section{PENDAHULUAN}

Badan Kepegawaian, Pendidikan dan Pelatihan (BKPP) Kabupaten Sragen berdasarkan Peraturan Daerah Kabupaten Sragen Nomor 5 Tahun 2016 tentang Pembentukan dan Susunan Perangkat Daerah merupakan salah satu organisasi perangkat daerah dengan perubahan beberapa tupoksi. Oleh karenanya BKPP Kabupaten Sragen harus memiliki rencana strategis sebagai pedoman pelaksanaan program dan kegiatan dalam rangka mewujudkan kinerja sebagaimana diamanatkan oleh Kepala Daerah. BKPP Kabupaten Sragen harus menyusun dokumen rencana strategis yang memuat arah kebijakan, strategi, program dan indikasi kegiatan guna mewujudkan kinerja dalam 5 tahun mendatang. Dalam konteks ini, pengenalan terhadap budaya organisasi menjadi penting agar dapat membentuk komitmen kolektif anggota organisasi dalam mencapai tujuan bersama.

Gerloff dalam Kusdi

(2011:23) menyatakan bahwa esensi permasalahan dalam organisasi adalah bagaimana menyeimbangkan antara kebutuhan individu akan kebebasan bertindak dengan kebutuhan organisasi akan kepatuhan para anggotanya demi mencapai tujuan bersama. Organisasi akan menjadi kaku dan tidak responsif jika individu tidak diberi ruang yang memadai untuk mengambil inisiatif dalam memecahkan masalah. Di sinilah perlunya upaya untuk mengorganisasi individu ke dalam tujuan bersama tanpa mengesampingkan kreativitas dan inisiatif pribadi. Dengan demikian, para manajer perlu memahami kultur yang berkembang di dalam organisasi agar proses actuating mendapat dukungan dan dilaksanakan sepenuh hati oleh segenap anggota organisasi.
Pencapaian kinerja organisasi merupakan suatu proses manajerial yang menuntut kapasitas kepemimpinan khususnya dalam mengelola suatu working team yang memiliki karakteristik tertentu yang dikenal sebagai budaya organisasi. Fungsi budaya organisasi adalah memberi identitas organisasi yang menunjukkan ciri khas yang berbeda dengan organisasi lain dan memfasilitasi komitmen kolektif anggota organisasi mempunyai normanorma dalam organisasi yang harus diikuti dan tujuan bersama yang harus dicapai (Kreitner dan Kinicki, 2003).

Oleh karena itu, unsur pimpinan perlu mengenali budaya organisasi apa yang berkembang dan menjadi harapan para anggota organisasi di masa mendatang. Hal ini menjadi penting karena pada hakikatnya proses pencapaian kinerja organisasi melibatkan interaksi antar manusia yang meliputi nilai-nilai, sikap dan perilaku, yang kesemuanya itu saling mempengaruhi.

Budaya organisasi merujuk pada suatu sistem pengertian bersama yang dipegang oleh anggota-anggota suatu organisai, yang membedakan organisasi tersebut dari organisasi lain. Sistem pengertian bersama ini, dalam pengamatan yang lebih seksama, merupakan serangkaian karakter penting yang menjadi nilai bagi suatu organisasi. (Deby Aprilia dalam Megawati, Nashri, 2015). Budaya organisasi dapat sangat beragam karena bervariasinya sumber daya manusia, baik dilihat dari segi gender, umur, ras, suku, tingkat pendidikan, pengalaman, maupun latar belakang budayannya. Untuk mengatasi masalah tersebut diperlukan pengelolaan keberagaman budaya. Dengan demikian, diharapkan organisasi mampu mengelola keberagaman dengan mengubah dari 
sifatnya sebagai hambatan menjadi sebuah kekuatan budaya organisasi.

Dalam rangka pencapaian kinerja BKPP Kabupaten Sragen diperlukan upaya identifikasi jenis budaya kerja organisasi yang ada dalam organisasi saat ini dan budaya kerja yang diharapakan oleh pegawai BKPP Kabupaten Sragen. Hal ini akan menjadi masukan yang berarti dalam menyusun strategi pencapaian kinerja dalam Renstra BKPP. Bertitik tolak dari hal-hal tersebut di atas, penulis tertarik untuk melakukan penelitian kecil dalam rangka menemukenali jenis budaya organisasi saat ini dan yang menjadi harapan para pegawai BKPP Kabupaten Sragen.

Berdasarkan hal tersebut, penulis merumuskan masalah penelitian ini sebagai berikut:

1. Budaya Organisasi apa yang saat ini berkembang di BKPP Kabupaten Sragen?

2. Budaya Organisasi apa yang menjadi harapan para pegawai BKPP Kabupaten Sragen di masa mendatang?

\section{METODE}

Jenis penelitian ini adalah penelitian deskriptif dengan pendekatan kuantitatif, yang merupakan studi untuk menemukan fakta dengan interpretasi yang tepat. Data yang digunakan adalah data kuantitatif yang didapatkan dari metode survey. Survey dilakukan terhadap seluruh pegawai di lingkungan BKPP Kabupaten Sragen dengan menggunakan kuesioner yang diadaptasi dari Ray Rangkuti (2015).
Populasi dalam penelitian ini adalah pegawai BKPP Kabupaten Sragen yang seluruhnya berjumlah 65 orang yang sudah berstatus PNS. Dengan jumlah populasi ini teknik sampling yang digunakan adalah sampling jenuh, di mana seluruh anggota populasi adalah merupakan sampelnya.

Data primer dalam penelitian ini dikumpulkan melalui kuesioner yang dikembangkan oleh Kim Cameron dan Robert Quinn yang dikenal sebagai Organizational Cultural Assessment Instrument (OCAI). Di dalam kuesioner ini terdapat 24 pertanyaan yang dikelompokkan ke dalam enam dimensi yang menggambarkan tipe-tipe budaya organisasi, yang terdiri dari clan, adhocracy, market dan hierarchy. Pengukuran OCAI dilakukan berdasarkan ipsative rating scale, dimana responden diminta untuk membagi angka 100 kepada empat alternative jawaban yang mencerminkan budaya organisasi. Skala ini digunakan agar responden melihat bahwa tipe-tipe budaya organisasi bukanlah hal yang terpisah. Hal ini menggambarkan prinsip yang dipegang oleh Cameron dan Quinn bahwa keempat tipe budaya di dalam setiap organisasi (Kusdi, 2011:269).

Pengolahan data dilakukan dengan menjumlahkan data pada setiap pertanyaan dan kemudian dibagi dengan jumlah responden. Selanjutnya, data yang merupakan rata-rata dari jawaban responden (sel), dijumlahkan lagi dengan data dari sel yang sama dan kemudian dibagi dengan 6. Hal ini dilakukan juga terhadap sel-sel lainnya. 
Tabel 1. Pengolahan Data OCAI

\begin{tabular}{|c|l|c|c|c|c|}
\hline No & \multicolumn{1}{|c|}{ Dimensi } & Clan & Adhocracy & Market & Hierarchy \\
\hline 1. & Karakteristik Dominan & A1 & B1 & C1 & D1 \\
3. & Kepemimpinan Organisasi & A2 & B2 & C2 & D2 \\
4. & Perekat Organisasi & A3 & B3 & C3 & D3 \\
5. & Strategi yang ditekankan & A4 & B4 & C4 & D4 \\
6. & Kriteria Keberhasilan & A6 & B6 & C6 & D5 \\
\hline & RATA-RATA & & & & D6 \\
\hline
\end{tabular}

Sumber: Kusdi (2011)

Penghitungan skor OCAI dilakukan secara terpisah antara kultur sekarang (now) dengan skor kultur yang dikendaki (preferred) agar dapat dilakukan pembandingan. Diagnosis kultur organisasi yang dapat dilakukan melalui tabulasi skor OCAI ini meliputi:

a. Tipe kultur yang mendominasi organisasi.

b. Kesenjangan antara kultur saat ini dan kultur yang diharapkan.

c. Kekuatan tipe kultur yang mendominasi organisasi.

d. Konkurensi profil kultur dari aspekaspek yang berbeda dan individuindividu yang berbeda dalam organisasi.

e. Perbandingan profil kultur organisasi dengan rata-rata profil kultur organisasi sejenis.

f. Kesesuaian organisasi dengan berbagai kecencerungan umum kultur organisasi abad ke-21.

Pada penelitian ini, diagnosis dibatasi pada tiga aspek pertama, yaitu kultur yang dominan, kesenjangan saat ini dan yang diharapkan, kekuatan kultur dan konkurensi profil kultur. Selanjutnya, dominasi tipe kultur akan ditunjukkan oleh skor tertinggi. Skor tersebut akan diinterpretasikan ke dalam bentuk diagram radar sehingga terlihat kecenderungan tipe budaya organisasi sehingga dapat dilakukan perbandingan sebagaimana disebutkan di atas.

Dalam penelitian ini, penulis menggunakan instrument OCAI yang sudah jadi. Berkenaan dengan reliabilitas dan validitas dari instrument tersebut, kiranya sudah cukup teruji sebagaimana disarankan oleh Rangkuti (2015:32) dan Kusdi (2011:269). Instrumen yang disusun berdasarkan model Competing Values ini ini telah dikembangkan sejak tahun 1991 oleh banyak ahli hingga kepada formatnya yang terakhir kali disempurnakan oleh Kim Cameron dan Robert Quinn. Instrument OCAI memiliki kadar kesederhanaan, keterukuran dan akuntabilitas yang memadai untuk diterapkan (Suderman, 2012).

\section{HASIL DAN PEMBAHASAN}

Setelah melakukan pengumpulan kuesioner yang telah diisi oleh para responden, maka data hasil kuesioner 
tersebut ditabulasikan ke dalam matriks OCAI berdasarkan kelompok-kelompok responden. Dalam hal ini, responden dikelompokkan menjadi kelompok pejabat struktural, pejabat fungsional widyaiswara, dan pejabat fungsional umum. Namun, untuk mengidentifikasi budaya organisasi saat ini dan yang diharapkan di BKPP
Kabupaten Sragen secara keseluruhan, data tersebut digabungkan.

Berdasarkan penghitungan matriks OCAI, budaya organisasi yang saat ini berlaku di BKPP Kabupaten Sragen menurut para responden adalah budaya Clan.

Tabel 2. Budaya Organisasi BKPP Saat Ini

\begin{tabular}{|l|l|l|}
\hline No. & BUDAYA & SKOR \\
\hline 1. & Clan & 26.483 \\
\hline 2. & Adhocracy & 21.667 \\
\hline 3. & Market & 22.45 \\
\hline 4. & Hierarchy & 26.117 \\
\hline
\end{tabular}

Sumber: Hasil pengolahan data.

Dari tabel di atas terlihat bahwa menurut para pegawai BKPP Kabupaten Sragen, budaya organisasi di unit kerja ini cenderung mengarah kepada budaya Clan. Namun, kiranya tidak terlalu dominan karena selisih yang tidak begitu jauh dengan tipe-tipe budaya lainnya. Untuk lebih jelasnya, dapat dilihat dalam diagram radar berikut:

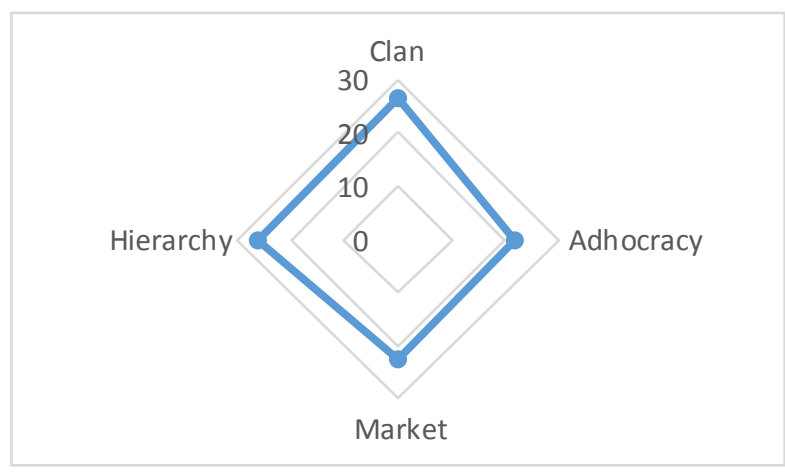

Grafik 1. Budaya Organisasi BKPP Saat Ini

Sumber: Hasil Pengolahan Data

Hal ini menggambarkan bahwa para pegawai lebih mempersepsikan diri sebagai sebuah keluarga besar dibanding suatu entitas ekonomi atau organisasi yang hirarkhis. Dalam organisasi yang berbudaya Clan ini, pemimpin diposisikan sebagai seorang pembimbing (mentor).

Setelah mengidentifikasi kondisi budaya organisasi pada BKPP Kab. Sragen pada saat ini, maka perlu diketahui pula apakah memang tipe budaya Clan ini merupakan budaya organisasi yang ideal atau diharapkan oleh para pegawai di BKPP di masa mendatang? Pertanyaan ini menjadi penting untuk mengetahui kekuatan budaya organisasi dan menjadi bahan masukan bagi unsur pimpinan dalam 
merumuskan strategi pencapaian kinerja organisasi di masa mendatang.
Hasil penghitungan skor untuk budaya organisasi yang diharapkan adalah sebagaimana tabel berikut:

Tabel 3. Budaya Organisasi BKPP Yang Diharapkan

Sumber: Hasil pengolahan data.

\begin{tabular}{|l|l|l|}
\hline No. & BUDAYA & SKOR \\
\hline 1. & Clan & 27.80 \\
\hline 2. & Adhocracy & 23.22 \\
\hline 3. & Market & 23.67 \\
\hline 4. & Hierarchy & 25.58 \\
\hline
\end{tabular}

Dari hasil tersebut, terlihat bahwa skor tertinggi adalah tipe budaya organisasi Clan. Hal ini berarti bahwa para pegawai di BKPP masih ingin mempertahankan tipe budaya organisasi yang berlaku saat ini.
Bahkan apabila kita lihat diagram/grafik radar di bawah ini, harapan akan tipe budaya Clan ini cukup signifikan mendominasi dibandingkan dengan tipe budaya lainnya.

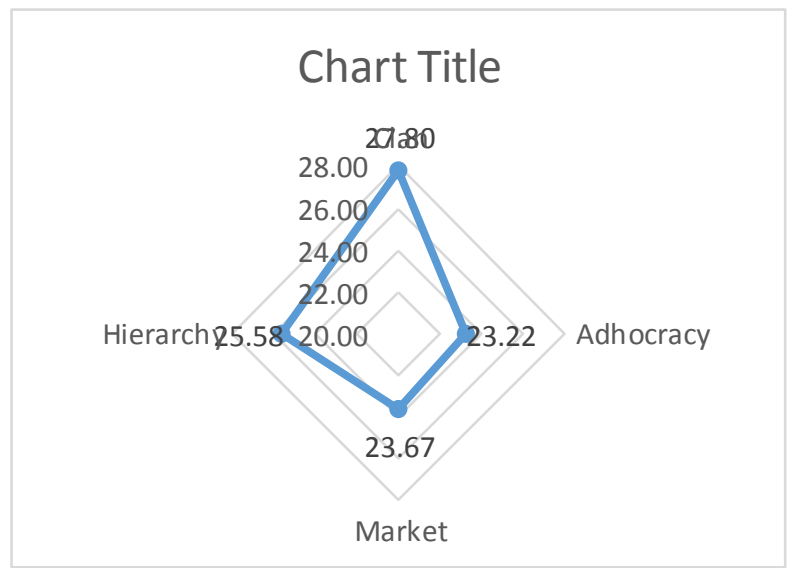

Grafik 2. Budaya Organisasi BKPP Yang Diharapkan Sumber : Hasil Pengolahan Data

Apabila dibandingkan dengan tipe budaya organisasi saat ini, terlihat bahwa berdasarkan harapan para pegawai, akan terjadi penguatan terhadap tipe budaya
Clan di masa mendatang. Hasil perhitungan instrument OCAI yang menguatkan hal ini adalah sebagai berikut:

Tabel 4. Perbandingan Budaya Organisasi BKPP Saat Ini Dengan Yang Diharapkan

\begin{tabular}{|l|l|l|c|c|}
\hline No. & BUDAYA & SAAT INI & DIHARAPKAN & SELISIH \\
\hline 1. & Clan & 26.483 & 27.80 & 1.317 \\
\hline 2. & Adhocracy & 21.667 & 23.22 & 1.553 \\
\hline 3. & Market & 22.45 & 23.67 & 1.22 \\
\hline 4. & Hierarchy & 26.117 & 25.58 & -0.537 \\
\hline
\end{tabular}


Sesungguhnya, peningkatan yang lebih signifikan terjadi pada tipe budaya Adhocracy. Dalam hal ini berarti bahwa para pegawai juga menginginkan adanya inovasi, kreativitas dan kultur yang dinamis (Kusdi, 2011:87). Secara sederhana, bisa diartikan bahwa pertumbuhan organisasi yang dinamis tersebut masih dalam bingkai organisasi yang guyub, dengan tingkat kepercayaan yang tinggi dan berfokus kepada sumber daya manusia (Zammuto dan Krakower dalam Kusdi, 2011:93). Gambaran mengenai pergeseran preferensi pegawai terhadap budaya organisasi ini dapat dilihat pada grafik berikut:

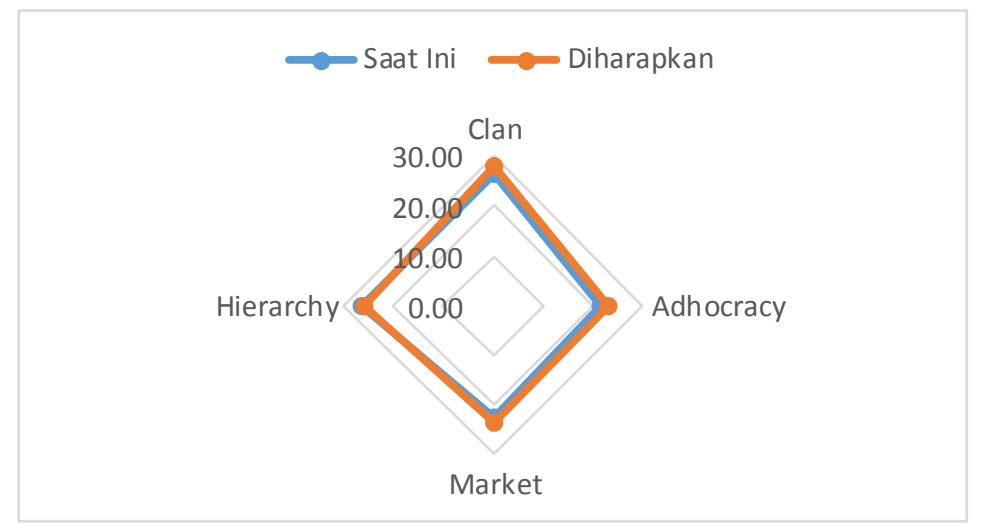

Grafik 3.Perbandingan Budaya Organisasi BKPP Saat Ini Dengan Yang Diharapkan

Hal yang cukup menarik adalah bahwa para pegawai menginginkan berkurangnya suasana hirarkhi di dalam organisasi. Apabila dikaitkan dengan menguatnya tipe Adhocracy, ini dapat berarti bahwa para pegawai menginginkan ruang yang lebih luas untuk kreativitas. Untuk lebih jelasnya, akan dilihat dengan membahas pergeseran antar dimensi pada masingmasing tipe budaya.

Pada bagian sebelumnya telah dikemukakan bahwa tipe budaya Clan merupakan budaya organisasi di BKPP dan pegawai masih mengharapkan tipe budaya tersebut di masa mendatang. Hal ini merupakan hasil perhitungan dari keseluruhan dimensi dalam budaya organisasi. Setelah diperjelas dengan grafik radar, terlihat bahwa selain tipe budaya Clan yang tetap diharapkan oleh anggota organisasi, kekuatan budaya market juga menunjukkan perubahan yang berarti. Pergeseran yang cukup signifikan adalah menguatnya ciri budaya Adhocracy dan berkurangnya harapan akan tipe budaya Hierarchy. Apabila kita merujuk kepada pengertian masing-masing tipe budaya, bisa diartikan bahwa pegawai menginginkan ruang kreativitas yang lebih besar dan kontrol yang berkurang. Namun, hal ini masih harus dibuktikan lagi mengingat setiap tipe budaya dibentuk oleh dimensi-dimensi yang berbeda.

Kesenjangan antara budaya saat ini dengan budaya yang diharapkan kiranya perlu dikupas lebih dalam dengan melihat kesenjangan antar dimensi dalam budaya organisasi. Sebagaimana telah dikemukakan pada bab sebelumnya, dimensi-dimensi tersebut terdiri dari Karakter Dominan, Kepemimpinan Organisasi, Manajemen Personil, Perekat Organisasi, Strategi yang Ditekankan dan Kriteria Keberhasilan. Penelaahan terhadap pergeseran budaya berdasarkan dimensi-dimensinya akan memberikan 
penjelasan yang lebih rinci sehingga diharapkan dapat menghasilkan masukan bagi manajemen organisasi untuk mengenali pada dimensi mana para anggota organisasi ingin ditingkatkan dan dimensi mana ingin dikurangi.
Gambaran mengenai pergeseran atau kesenjangan antar dimensi-dimensi dalam budaya organisasi saat ini dan yang diharapkan pada BKPP Kabupaten Sragen adalah sebagaimana tabel berikut:

Tabel 5 Pergeseran Dimensi-Dimensi Budaya Organisasi Pada BKPP Kab. Sragen

\begin{tabular}{|c|c|c|c|c|}
\hline & & SAATINI & HARAPAN & SELISIH \\
\hline \multicolumn{5}{|c|}{ \#1 Karakter Dominan } \\
\hline 1 & Clan & 29.30 & 26.10 & -3.20 \\
\hline 2 & Adhocracy & 20.90 & 23.30 & 2.40 \\
\hline 3 & Market & 25.20 & 25.40 & 0.20 \\
\hline 4 & Hierarchy & 23.60 & 25.00 & 1.40 \\
\hline \multicolumn{5}{|c|}{ \#2 Kepemimpinan Organisasi } \\
\hline 1 & Clan & 26.40 & 28.90 & 2.50 \\
\hline 2 & Adhocracy & 23.30 & 23.30 & 0.00 \\
\hline 3 & Market & 23.90 & 23.70 & -0.20 \\
\hline 4 & Hierarchy & 26.20 & 24.30 & -1.90 \\
\hline \multicolumn{5}{|c|}{ \#3 Manajemen Personil } \\
\hline 1 & Clan & 25.00 & 28.60 & 3.60 \\
\hline 2 & Adhocracy & 23.30 & 22.50 & -0.80 \\
\hline 3 & Market & 23.30 & 22.70 & -0.60 \\
\hline 4 & Hierarchy & 28.60 & 26.30 & -2.30 \\
\hline \multicolumn{5}{|c|}{ \#4 Perekat Organisasi } \\
\hline 1 & Clan & 27.80 & 26.70 & -1.10 \\
\hline 2 & Adhocracy & 22.60 & 24.50 & 1.90 \\
\hline 3 & Market & 21.70 & 23.90 & 2.20 \\
\hline 4 & Hierarchy & 28.00 & 25.80 & -2.20 \\
\hline \multicolumn{5}{|c|}{ \#5 Strategi yang Ditekankan } \\
\hline 1 & Clan & 26.60 & 28.40 & 1.80 \\
\hline 2 & Adhocracy & 21.20 & 23.80 & 2.60 \\
\hline 3 & Market & 21.60 & 23.10 & 1.50 \\
\hline 4 & Hierarchy & 29.80 & 25.10 & -4.70 \\
\hline \multicolumn{5}{|c|}{ \#6 Kriteria Keberhasilan } \\
\hline 1 & Clan & 23.80 & 28.10 & 4.30 \\
\hline 2 & Adhocracy & 18.70 & 21.90 & 3.20 \\
\hline 3 & Market & 19.00 & 23.20 & 4.20 \\
\hline 4 & Hierarchy & 20.50 & 27.00 & 6.50 \\
\hline
\end{tabular}

Sumber: Hasil Pengolahan Data

Dari tabel di atas, terlihat bahwa meskipun para pegawai BKPP masih mengharapkan keberlanjutan tipe budaya Clan, namun ternyata tidak semua dimensi menunjukkan adanya kesenjangan positif terhadap tipe budaya tersebut. Kesenjangan positif terjadi pada dimensi Kepemimpinan Organisasi, Manajemen Personil, Strategi yang Ditekankan dan Kriteria Keberhasilan. Dalam hal ini, para responden masih sangat mengharapkan Kepemimpinan dalam organisasi ini bersifat sebagai mentor, adanya keterbukaan, partisipasi, pengembangan SDM, teamwork dan kepedulian antar anggota organisasi.

Di sisi lain, para responden juga mengharapkan meningkatnya corak budaya Adhocracy. Hal ini ditunjukkan oleh kesenjangan positif pada lima dimensi. Meskipun tidak merubah preferensi budaya organisasi, namun peningkatan ini cukup signifikan dan tergambarkan dengan jelas pada grafik 3 . Berdasarkan tabel di atas, tergambar harapan para responden akan organisasi 
yang dinamis, kepemimpinan yang lebih inovatif dan berani mengambil resiko, pengelolaan SDM yang lebih memberikan ruang bagi kebebasan dan keunikan individu, serta focus pada inovasi dan halhal paling mutakhir.

Upaya pencapaian kinerja organisasi telah dipahami sebagai pekerjaan dari suatu tim yang melibatkan keseluruhan anggota organisasi. Dalam hal ini, seringkali manajemen organisasi hanya berfokus pada system pembagian kerja dengan division of labour, target produktivitas (kinerja) yang ketat dan berbagai mekanisme control (Kusdi, 2011:13). Namun, aspek manusia sebagai penggerak organisasi seringkali diabaikan. Hal inilah yang seringkali menjadi acuan dalam teori dan praktek organisasi klasik di mana para pengambil keputusan hanya memusatkan pada faktor-faktor internal yang ada pada organisasi.

Kemajuan teknologi, perubahan sosial dan pergaulan global membuat perhatian terhadap budaya organisasi menjadi semakin signifikan karena persinggungan antar budaya menjadi tidak terelakkan. Hal ini mengakibatkan meningkatnya intensitas perubahan dalam suatu organisasi. Para anggota organisasi merupakan suatu kelompok yang berinteraksi secara regular dan berulang-ulang sehingga memunculkan suatu pola keteraturan berupa nilai-nilai dalam organisasi. Dalam kaitannya dengan pencapaian kinerja organisasi, para pengambil keputusan dan manajemen kiranya tidak dapat lagi mengabaikan aspek intangible ini karena manusialah yang akan bergerak secara dinamis dalam rangka pencapaian kinerja tersebut. Melalui pengenalan terhadap budaya organisasi baik yang saat ini berlaku maupun yang menjadi harapan para anggota organisasi, maka pihak manajemen akan mendapatkan masukan yang sangat penting guna mengelola para pegawai/anggota organisasi dalam rangka penyusunan strategi pencapaian kinerja.

Berdasarkan hasil pengolahan data jawaban responden terhadap kuesioner OCAI, budaya organisasi yang diharapkan oleh pegawai BKPP dimasa yang akan datang masih sama dengan budaya organisasi yang dominan saat ini yaitu tipe Clan. Sementara itu tipe Adhocracy juga mendapatkan peningkatan preferensi meskipun skor nya masih jauh dibawah tipe Clan.

\section{PENUTUP}

Organisasi digerakkan oleh individuindividu yang memiliki perilaku-perilaku tertentu. Dalam konteks kumpulan individu di dalam organisasi, perilakuperilaku tersebut bersama nilai-nilai yang muncul dalam interaksi membentuk budaya organisasi. Aspek ini semakin mendapat perhatian khususnya terkait dengan upaya pimpinan dan manajemen dalam rangka mewujudkan kinerja organisasi. Hal ini juga berlaku pada BKPP Kabupaten Sragen yang mengalami perubahan struktur dari Badan Kepegawaian Daerah sehingga dapat diprediksi akan terjadi perubahan yang signifikan dalam penyusunan dan pelaksanaan Rencana Strategisnya.

Melalui identifikasi terhadap aspek budaya organisasi pada BKPP, diharapkan tersedianya masukan bagi unsur pimpinan unit kerja dalam penyusunan strategi pencapaian kinerja sebagaimana ditargetkan di dalam dokumen perencanaan tersebut. Melalui penelitian ini, diketahui bahwa budaya organisasi yang dominan di BKPP saat ini adalah tipe Clan, dimana organisasi adalah seperti keluarga besar, mengutamakan komitmen 
bersama, partisipasi dan pengembangan sumber daya manusia. Harapan para pegawai di masa mendatang juga tidak berubah, yaitu masih menginginkan budaya organisasi tipe Clan. Untuk budaya Hierarchy diharapkan berkurang perannya sementara tipe budaya Adhocracy justru meningkat. Ini berarti selain suasana kekeluargaan dalam tipe Clan, pegawai juga berharap akan organisasi yang dinamis, kepemimpinan yang lebih inovatif dan berani mengambil resiko, pengelolaan SDM yang lebih memberikan ruang bagi kebebasan dan keunikan individu, serta focus pada inovasi dan halhal paling mutakhir.

Berdasarkan hasil identifikasi budaya organisasi di BKPP Kabupaten Sragen tersebut maka Pimpinan perlu memperhatikan bahwa para anggota organisasi masih sangat mengharapkan kepemimpinan dalam organisasi ini bersifat sebagai mentor, mengharapkan adanya keterbukaan, partisipasi, pengembangan SDM, teamwork dan kepedulian antar anggota organisasi. Pimpinan juga harus memperhatikan bahwa anggota organisasi juga menginginkan adanya inovasi, ruang berkreasi dan keberanian mengambil resiko. Selain itu perlu adanya strategi yang tepat untuk mempertahankan budaya yang baik dan mendorong penumbuhan aspek positif dari tipe budaya lainnya.

\section{DAFTAR PUSTAKA}

Kreitner, Robert dan Angelo Kinicki. 2003. Perilaku Organisasi. Jakarta: Salemba Empat.

Kusdi. 2011. Budaya Organisasi: Teori, Penelitian dan Praktik. Jakarta: Salemba Empat.

Megawati, M. Fauzan Nasri. 2015. Evaluasi Budaya Organisasi Dalam Penerapan Teknologi Informasi Menggunakan Organizational Culture Assessment Instrument (Ocai) Pada Pt. Perkebunan Nusantara V Pekanbaru : Jurnal Rekayasa dan Manajemen Sistem Informasi, Vol. 1, No. 1.

OCAI Reports. 2012. Www.ocai-online.com/userfiles/file/ocai_enterprise_example_ report.pdf diakses tanggal 25 Mei 2017.

Rangkuti, Freddy. 2015. SWOT Balanced Scorecard. Jakarta: Gramedia Pustaka Utama. 2017.

Suderman, J. 2012. Using The Organizational Assessment (OCAI) as a Tool for New Team Development: Journal of Practical Consulting, Vol. 4. Virginia : Regent University School of Business and Leadership. 